\title{
Chinese herb mix Tiáo-Gēng-Tāng possesses antiaging and antioxidative effects and upregulates expression of estrogen receptors alpha and beta in ovariectomized rats
}

Lian-wei $\mathrm{Xu}^{1,2^{*}}$, Lan Kluwe ${ }^{3}$, Ting-ting Zhang ${ }^{1}$, Sheng-nan $\mathrm{Li}^{1}$, Yan-yan Mou' ${ }^{1}$ Zhen Sang ${ }^{4}$, Jun Ma ${ }^{5}$, Xiong $\mathrm{Lu}^{5}$ and Zhuo-jun Sun ${ }^{4}$

\begin{abstract}
Background: Herb mixtures are widely used as an alternative to hormonal therapy in China for treatment of the menopausal syndrome. However, composition of these herb mixtures are complex and their working mechanism is often unknown. This study investigated the effect of Tiáo-Gēng-Tāng (TG-decoction), a Chinese herbal mixture extract, in balancing female hormones, regulating expression of estrogen receptors (ERs), and preventing agingrelated tissue damage.
\end{abstract}

Methods: Ovariectomized 5-month-old female rats were used to model menopause and treated with either TGdecoction or conjugated estrogen for 8 weeks. Estradiol $\left(E_{2}\right)$, luteinizing hormone $(\mathrm{LH})$ and follicle-stimulating hormone (FSH) were measured in serum and in the hypothalamus. Hypothalamic expression of estrogen receptor (ER) alpha and beta were studied by real-time PCR and western blotting. Total antioxidant capacity (T-AOC), oxidation indicator superoxide dismutase (SOD) activity and tissue damage parameter malondialdehyde (MDA) were measured using standard assays. Aging-related ultrastructural alterations in mitochondria were studied in all animals by transmission electron microscopy.

Results: TG-decoction-treatment elevated $E_{2}$ and lowered FSH in serum of ovariectomized rats. The potency and efficacy of TG-decoction on the hypothalamus was generally weaker than that of conjugated estrogens. However, TG-decoction was superior in upregulating expression of ER $\alpha$ and $\beta$. TG-decoction increased hypothalamic SOD and T-AOC levels and decreased MDAlevels and mitochondrial damage in hypothalamic neurons.

Conclusions: TG-decoction balances female hormones similarly to conjugated estrogens but less effectively. However, it is superior in up regulating $E R \alpha$ and $\beta$ and exhibits antioxidative antiaging activities. Whilst it shares similar effects with estrogen, TG-decoction also seems to have distinctive and more complex functions and activities.

\section{Background}

Estrogen therapy is regarded as standard treatment for the menopausal syndrome, which is caused by rapid decrease and fluctuation of female hormones [1]. However, estrogen substitution is also associated with side effects including endometrial hyperplasia, increased risk

\footnotetext{
* Correspondence: sherryxlw@hotmail.com

'Gynecology Department, Shanghai Yueyang Integrated Traditioanl Chinese Medicine and Western Medicine Hospital affiliated to Shanghai University of Traditional Chinese Medicine, Gan He Road 110, Shanghai, China Full list of author information is available at the end of the article
}

of certain cancer types (breast and ovarian cancer and endometrial carcinoma), liver abnormalities, and hematological adverse effects (coronary heart disease, stroke and venous thromboembolism) [2-7]. Recently, alternative therapies using natural products with milder efficacy but fewer side effects have been studied, herb mixtures of traditional Chinese medicine (TCM) being one such alternative therapy studies.

Tiáo Gēng Tāng (TG-decoction) meaning "decoction which regulates body balances in menopause", is among 
these Chinese herb mixtures, and has been used to treat symptoms of menopause in China for more than 30 years. According to the TCM theory, the menopausal syndrome is caused by kidney-liver weakness-based yinyang imbalance and organ disharmony [8]. TG-decoction consists of 10 herbs (Table 1) and is composed to strengthen kidney and liver function, to nourish deficient essence in organs, to disperse excessive fire from the body, and finally to balance yin and yang.

In conventional medicine, this alternative rationale is difficult to be explained scientifically although conventional medicine and TCM share a common understanding of pathological mechanisms of menopause to be an aging-related disorder with decreasing estradiol $\left(E_{2}\right)$ levels. $E_{2}$ contributes to activate the antioxidant defense systems, scavenging reactive oxygen species (ROS) and thereby reduces aging-related damage in mitochondria, a key organelle in the development of aging-associated cellular damage $[9,10]$. Oxidative stress in the process of aging particularly affects the brain due to its high metabolic rate and reduced capacity for restoration compared to other organs [11].

Empirically and as studies have proven, TG-decoction is especially effective for treatment of hot flashes, sleep disturbance and emotional instability during menopause, with success rates of $66-90 \%$ [12]. It is known that TGdecoction elevates $\mathrm{E}_{2}$ and lowers follicle-stimulating hormone (FSH) in postmenopausal women [12]. These effects are similar to those of estrogen therapy and may explain some effects of the drug. However, more detailed studies on TG-decoction and its effects and side effects are lacking.

TG-decoction provides systemic therapy, and antiaging and antioxidative effects are expected and are addressed in the present study. We used ovariectomized rats as a model for the menopause and focused on the hypothalamus because this is the regulatory center for the neuroendocrine system [13], thermoregulation $[14,15]$, circadian rhythms [16], emotion [17], autonomic nervous system [18], and other functions that are frequently affected by menopausal hormonal changes [19]. We further studied estrogen receptor (ER) $\alpha$ and $\beta$ because previous works have hypothesized that decreased expression of these receptors contribute to reduced responsiveness of hypothalamus to estradiol during aging [20,21].

\section{Methods}

\section{Preparation of TG-Decoction}

TG-decoction is a decoction of 10 Chinese herbs as listed in Table 1. A typical daily dose for an adult is 166 g. All herbs were purchased from the Pharmacy Department of Shanghai Shuguang Hospital affiliated with Shanghai University of Traditional Chinese Medicine, China. The decoction was prepared in the laboratory of the Science and Technology Experiment Centre of Shanghai University of Traditional Chinese Medicine. All herbs were soaked in water in a ratio of $1 / 3(\mathrm{~g} / \mathrm{ml})$ for $30 \mathrm{~min}$ and subsequently boiled for a further 30 min. After saving the supernatant containing constituent extracted from the herbs, the same volume of water was added to the dregs and boiled for a further $30 \mathrm{~min}$. The two extracts were pooled together and concentrated by means of heating evaporation. The volume of the decoction was adjusted to $2 \mathrm{ml}$ for each rat. The decoction was stored at $4^{\circ} \mathrm{C}$ until the experiment.

\section{Animals and treatment}

All experimental procedures were evaluated and granted ethical approval by the National Natural Science Foundation, Beijing, China (approval number: 30772820). Rats were purchased from the Experimental Animal Centre of Shanghai University of Traditional Chinese Medicine (Certificate of Conformity: SCXK (Shanghai) 2008-0016) and cared for in the specific pathogen free conditions in the center. A total of 72 specific pathogen free Sprague-Dawley female rats were used. Three months after birth at a weight of $200 \pm 10 \mathrm{~g}, 54$ rats

Table 1 Compositions of TG-decoction

\begin{tabular}{|c|c|c|c|c|}
\hline Chinese name & Ping Yin & Latin name & Part used & daily adult Dose (g) \\
\hline 生地黄 & shēng di huáng & Radix rehmanniae & Dried root & 15 \\
\hline 白药 & bái sháo & Radix paeoniae alba & Dried root & 10 \\
\hline 巴戟天 & bā jí tiān & Radix morindae officinalis & Dried root & 9 \\
\hline 淫羊藿 & yín yáng huò & Herba epimedium & Dried herb & 15 \\
\hline 知母 & zhìmǔ & Rhizoma anemarrhenae & Dried rhizome & 9 \\
\hline 黄柏 & huáng bǎi & Cortex phellodendri & Dried bark & 9 \\
\hline 生龙骨 & shēng lóng gǔ & Os draconis & Fossil bone & 30 \\
\hline 生牡蚛 & shēng mǔ lì & Concha ostreae & shell & 30 \\
\hline 夜交藤 & yè jiāo téng & Caulis polygoni multiflori & Dried vine & 30 \\
\hline \multirow[t]{2}{*}{ 柴胡 } & chái hú & Radix bupleurum & Dried root & 9 \\
\hline & & & Total amount: & 166 \\
\hline
\end{tabular}


were bilaterally ovariectomized to create a model of the menopause [22], while the other 18 were left as young non-ovariectomized controls. The 54 ovariectomized rats were randomly divided into 3 groups (18 rats each) and assigned to: (1) untreated controls; (2) TG-decoction treatment; and (3) Premarin (conjugated estrogens tablets; Wyeth Pharmaceutical Co. Ltd., China) treatment. Treatments were started 1 week after bilateral ovariectomy under anesthesia with $3 \%$ sodium pentobarbital.

Using $166 \mathrm{~g}$ as the daily dose of dried herbs for an adult, the relative body surface-area ratio of rats to humans of $7: 1$, adult human weight of $60 \mathrm{~kg}$ and rat weight of $0.2 \mathrm{~kg}$, the daily dose of dried herbs for one rat was calculated as $3.87 \mathrm{~g}=166 \mathrm{~g} * 7 *(0.2 \mathrm{~kg} / 60 \mathrm{~kg})$, and that of Premarin as $0.015 \mathrm{mg} /$ rat. TG-decoction was given in 2-ml suspensions (corresponding to $3.87 \mathrm{~g}$ dried herbs) intragastrically once daily. Premarin was given the same way. Physiological saline was given to rats in the control group and to rats in the non-ovariectomized group. One day after 8 weeks treatment, serum and hypothalamus were sampled from all the treated and untreated rats for the following measurements. All specimens and samples were stored at $-80^{\circ}$ $\mathrm{C}$ until used for assay.

\section{Laboratory measurement}

FSH, LH and $\mathrm{E}_{2}$ in serum and hypothalamus were measured using standard radioimmunoassay and reagents (North Biotechnology Research Institute, Beijing, China) in the laboratory of the Science and Technology Experiment Centre of Shanghai University of Traditional Chinese Medicine. The measurement was carried out according to the protocol of the manufacturer.

SOD was measured using xanthine oxidase method, in which superoxide anion radicals lead to oxidation of hydroxylamine, resulting in a purple nitrite compound measurable by a spectrophotometer. SOD activity leads to reduction of the nitrite compound and thus lowers the absorbance. T-AOC assay was based on reduction of $\mathrm{Fe}^{3+}$ to $\mathrm{Fe}^{2+}$, whereas the latter forms complexes with phenanthroline substances, which can be measured using a spectrophotometer. MDA is measured using the thiobarbituric acid method in which MDA, the degradation product of lipid peroxidation, condenses with penthiobarbital and leads to a red product with measurable absorbance using a UV spectrophotometer.

Commercial assay kits for SOD, T-AOC and trace MDA were provided by Jiancheng Biotechnology Research Institute (First Branch) (Nanjing, China). Measurements were performed according the protocol provided by the manufacturer in the laboratory of the Science and Technology Experiment Centre, Shanghai University of Traditional Chinese Medicine.

\section{Expression of $E R \alpha$ and $\beta$}

Total RNA was prepared from the hypothalamus using TRIZOL reagent (Promega, Madison, WI, USA) and checked for quality by running them on a $1.2 \%$ agarose gel. Reverse transcription was carried out using PrimeScript RT Reagent Kit (TaKaRa BIO, Dalian, China) and subsequent real-time PCR was performed using SYBR Green Supermix (Bio-Rad, Hercules, CA, USA) with an iCycler ${ }^{\circledR}$ Thermal Cycler (Bio-Rad). GADPH was used as an internal reference to normalize levels of total mRNA in a sample. Relative expression of ER $\alpha$ and $\beta$ in ovariectomized rats (untreated, Premarin-treated or TGdecoction-treated) was calculated against expression of $E R \alpha$ and $\beta$ in non-ovariectomized rats. Primer sequences are available upon request.

Western blotting was performed as described previously [23]. For western blot analysis, protein was extracted from the hypothalamus, run on denaturing SDS-polyacrylamide gels and transferred onto blotting membranes. After blocking non-specific binding, the membranes were sequentially incubated with primary antibodies for ER $\alpha$ or $\beta$ (ABCAM, Boston, MA, USA), alkaline phosphatase-labeled secondary antibodies for the primary antibodies and visualized using BCIP/NBT as substrate (Promega). $\beta$-Actin was used as a protein quality and quantity control.

\section{Ultrastructure of hypothalamus mitochondria}

Sample preparation was carried as described previously [24]. Immediately after sampling, hypothalamus pellets were placed in ice-cold $2.5 \%$ glutaraldehyde solution for $2 \mathrm{~h}$. The specimens were washed four times in $0.2 \mathrm{M}$ cacodylate buffer, and post-fixed in $1 \% \mathrm{OsO}_{4}$ for $2 \mathrm{~h}$, then dehydrated in graded acetone steps, and embedded in Spurr's resin. Ultrathin sections were double stained with $2 \%$ uranyl acetate and lead citrate, and examined by transmission electron microscopy (Tecnai-12 Biotwin; Philips-FEI, Eindhoven, Netherlands) at magnifications of up to 43,000 .

\section{Statistical analysis}

Statistical analysis was carried out using SPSS15.0. Data with normal distribution were analyzed using one-way analysis of variance and least significant differences. Data that were not normally distributed were analyzed using the non-parametric Kruskal-Wallis and least significant difference tests. $\mathrm{P}<0.05$ was considered statistically significant.

\section{Results}

\section{TG-decoction regulates sexual hormones}

Bilateral ovariectomy significantly lowered $E_{2}$ levels and elevated FSH and LH in serum and hypothalamus of 5- 
month-old female rats (Figure 1), providing a menopause model [22].

When these ovariectomized rats were given TGdecoction or Premarin (conjugated estrogens), hormones in serum were regulated towards the normal status of non-ovariectomized control rats, meaning that $\mathrm{E}_{2}$ was increased while FSH was decreased (Figure 1A, B). The hormone-regulating effects of TG-decoction were

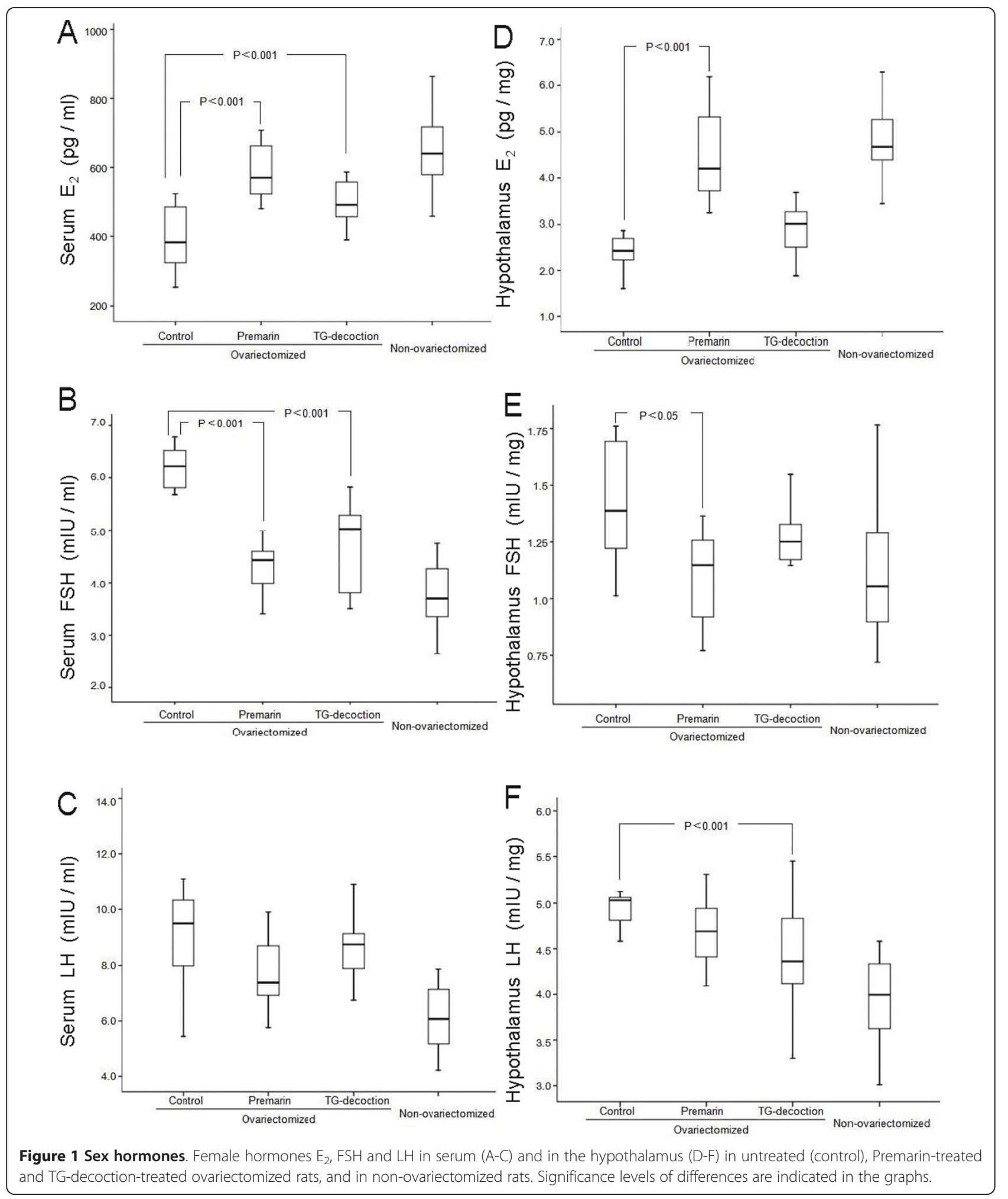


generally weaker than those of Premarin. For example, increased $\mathrm{E}_{2}$ and decreased FSH in the hypothalamus were only significant in rats treated with Premarin but not in those treated with TG-decoction (Figure 1D, E).

\section{Expression of ER $\alpha$ and $\beta$}

Both TG-decoction and Premarin slightly increased ER $\alpha$ and $\beta$ in ovariectomized rats at the mRNA and protein levels. The effect of TG-decoction was stronger than that of Premarin (Figure 2).

\section{Antioxidant activity and lipid peroxidation damage}

Bilateral ovariectomy significantly lowered SOD, one of the most important antioxidative enzymes [25] and total antioxidant capacity (T-AOC) [26], and elevated the indicator of lipid peroxidation damage malondialdehyde (MDA) [27]. Both TG-decoction and Premarin
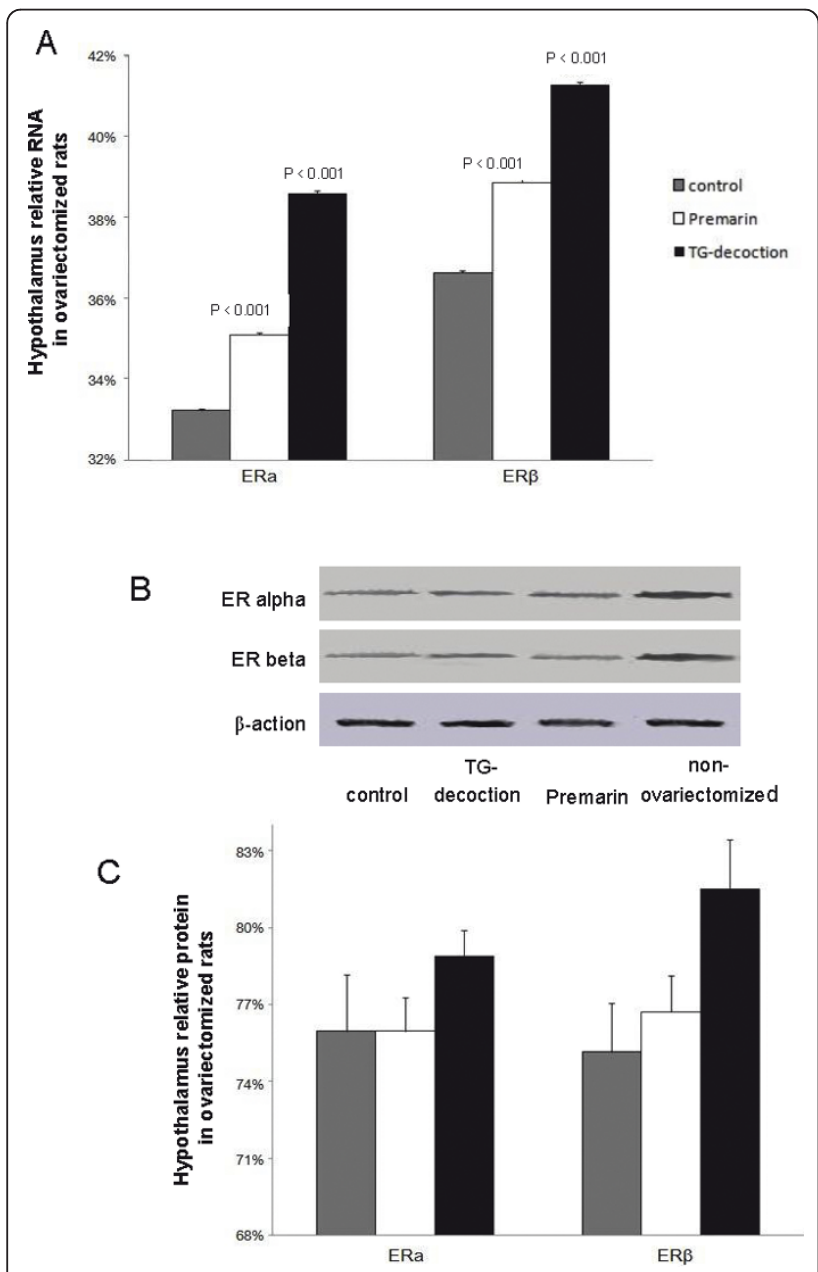

Figure 2 Expression of $E R \alpha$ and $\beta$. ER $\alpha$ and $\beta$ in ovariectomized rats at RNA $(A)$ and protein $(B, C)$ levels. B: Western blotting. Gray bars $=$ untreated, white bars $=$ Premarin-treated, black bars $=$ TGdecoction-treated ovariectomized rats. All values are relative to those of non-ovariectomized rats. significantly reversed these aging parameters by elevating SOD and T-AOC and lowering MDA in the hypothalamus of ovariectomized rats (Figure 3).

\section{Ultrastructural mitochondria alteration}

Electron microscopy revealed mitochondrial damage in hypothalamic neurons of ovariectomized rats, characterized by edema, swelling and vacuolization. Also, breakage of cristae was visible (Figure 4B, arrows). Both Premarin and TG-decoction treatment reduced these ultrastructural alterations (Figure 4D, F).

\section{Discussion}

Using ovariectomized rats as a model for the menopause, we found that TG-decoction (1) elevated $E_{2}$ in serum but not in the hypothalamus; (2) had antioxidative activity and tissue-protective function; and (3) upregulated expression of $\mathrm{ER} \alpha$ and $\beta$ in the hypothalamus.

The mild estrogen-like effects of TG-decoction are reasonable because several of its constituents are known to contain flavonoid aglycones (kaempferol, apigenin, quercetin, luteolin and breviflavone $\mathrm{B}$ ), which have estrogen-like activity [28]. The complete composition of this decoction is being elucidated in ongoing studies that may identify additional compounds with estrogenlike effects.

Results of previous studies regarding expression of ERs in ovariectomized rats and upon $\mathrm{E}_{2}$ treatment are controversial [29-32]. In our study, expression of ERs decreased in the hypothalamus of ovariectomized rats and increased upon treatment with TG-decoction. Similar results have been recently reported by Wu et al. [33] who have found that total flavonoids of Epimedium sagittatum reversed the markedly reduced ER $\alpha$ expression in the hypothalamus of ovariectomized rats. The impact of ovariectomy and estrogen treatment on the expression of $E R \alpha$ and $\beta$ varies in different parts of the rat brain $[34,35]$. Also, within the hypothalamus, ER expression may differ in various subregions during aging $[20,21]$. Further studies are necessary to find out how the expression of ERs in various subregions of the hypothalamus is influenced by the TG-decoction.

TG-decoction exhibited antiaging and tissue-protective activities in this study. Some of these activities may be direct and not mediated by ERs. In fact, antioxidative and cellular protective activities have been reported previously for several constituents of TG-decoction including yín yáng huò (Herba epimedium) [36], bā jí tiān (Radix morindae officinalis) [37], shēngdi huáng(Radix rehmanniae) [38] and zhimú (Rhizoma anemarrhenae) $[39,40]$. Phytoestrogens, for example, genistein in soya, are also known to be antioxidative by suppressing formation of reactive oxygen species and preventing release of cytochrome c from mitochondria [41]. Furthermore, 


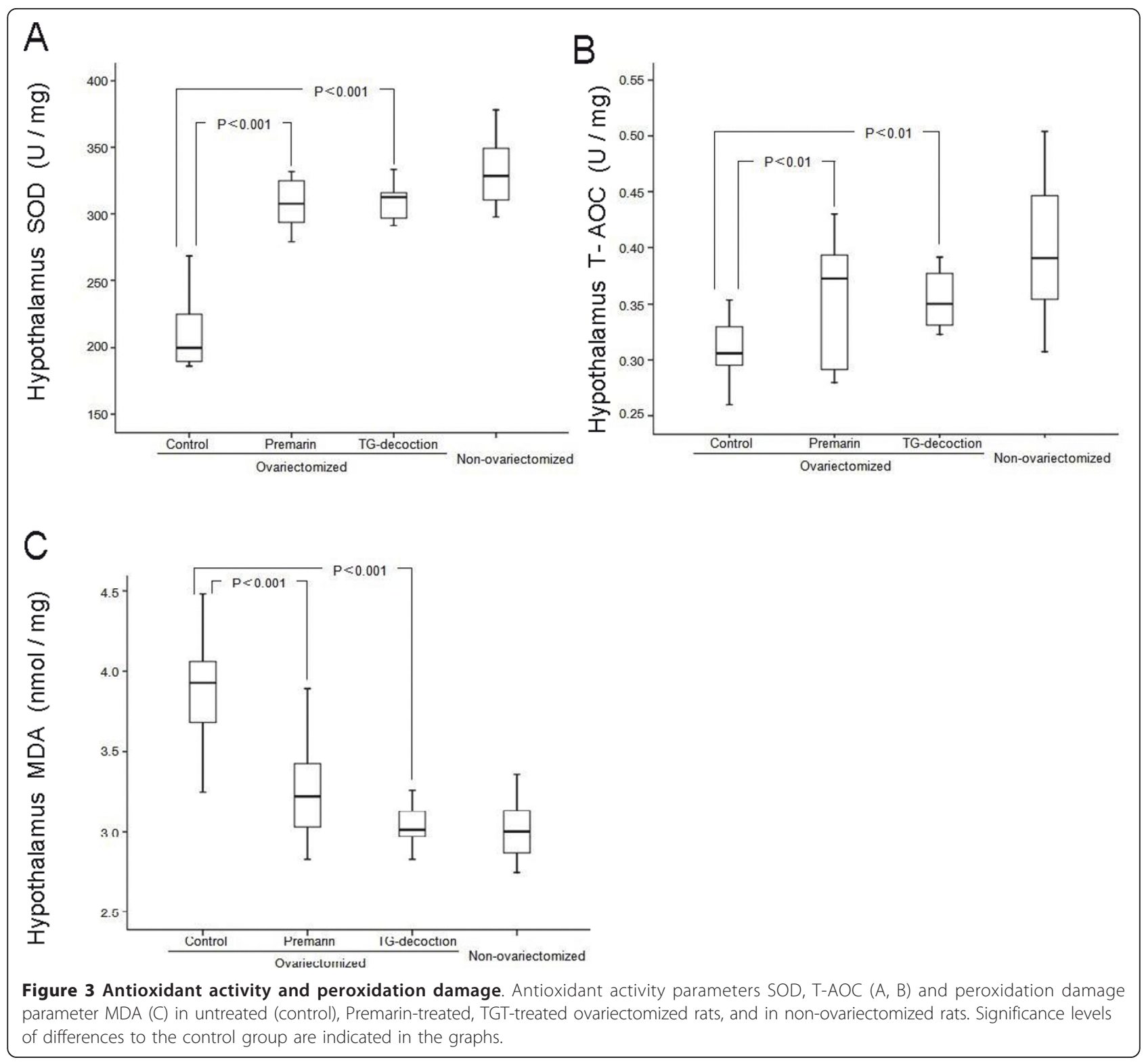

neuroprotective effects have been reported for quercetin (a phytoestrogen) and $17 \beta$-estradiol, which are probably not mediated via ERs but are rather based on their antioxidant and free radical scavenging properties [42].

Estrogenic activity of some compounds of the TGdecoction and their derivatives and/or metabolites may also indirectly contribute to the observed antiaging activities. Upon binding ERs, estrogen upregulates expression of antioxidant enzymes via intracellular signaling pathways $[41,43]$. Recently, ERs have been identified in mitochondria [44] and $E_{2}$ treatment has been reported to increase the level of ER $\alpha$ in mitochondria and to modulate mitochondrial function, resulting in greater energy-producing capacity and decreased reactive oxygen species production [45].
With regard to TCM, TG-decoction regulates balances of yin-yang, exterior-interior, cold-hot and deficiencyexcess, and thus ameliorates menopausal symptoms and overall body health, and contributes to general well being. To shed light on the mechanism of efficacy of this herb mixture in treating menopausal syndrome and in promoting global health, further studies are in progress, including those aiming to define the precise composition and identify targets of this herb mixture.

\section{Conclusions}

TG-decoction balances female hormones, exhibits antiaging and antioxidative activities, and upregulates ERs. On the one hand, it shares some similar effects with conjugated estrogens. On the other hand, its mechanism 

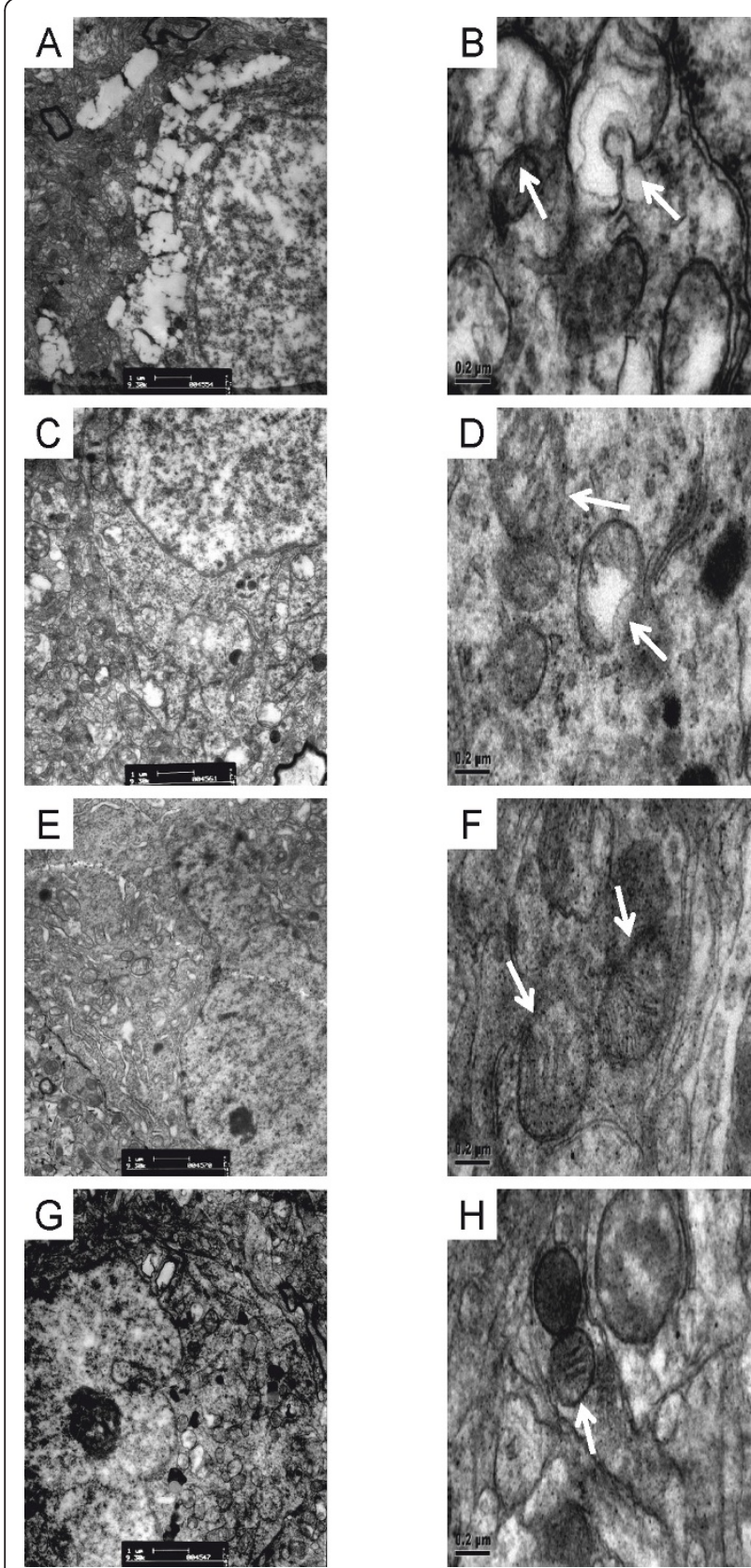

Figure 4 Ultrastructural mitochondria alteration. Ultrastructure of mitochondria of hypothalamic neurons in untreated (control), Premarin-treated, and TGT-treated ovariectomized rats, and in nonovariectomized rats, under electron microscopic magnification of $8,200(A, C, E, G)$ and $43,000(B, D, F, H)$. Mitochondrial damage is indicated by arrows.

of action seems to be more complex. Future studies should explore the constituents of TG-decoction and investigate their effects on expression of relevant genes and signaling pathways.

\section{Abbreviation list}

$\mathrm{E}_{2}$ : estradiol; ER $\alpha$ : estrogen receptor alpha; ER $\beta$ : estrogen receptor beta; ERs: estrogen receptors; FSH: folliclestimulating hormone; LH: luteinizing hormone; MDA: malondialdehyde; ROS: reactive oxygen species; SOD: superoxide dismutase; T-AOC: total antioxidant capacity; TCM: traditional Chinese medicine; TG-decoction: Tiáo Gēng Tāng

\section{Acknowledgements}

Funded by Shanghai Leading Academic Discipline Project supported by Science and Technology Commission of Shanghai (S30303) and National Natural Science Foundation of China (30772820). We thank professor Jianwen Liu and Huan-ying Zhang (College of Pharmacy, East China University of Science and Technology, Shanghai, China) for helping us in RT-PCR and Western-blotting analysis. The authors also thank Dr. Rosa Nguyen (Department of Pediatrics, University of Maryland, Baltimore, USA) for correcting the language and Dr. Qi Chen (Department of Obstetrics and Gynaecology, University of Auckland, New Zealand) for suggestions.

\section{Author details}

'Gynecology Department, Shanghai Yueyang Integrated Traditioanl Chinese Medicine and Western Medicine Hospital affiliated to Shanghai University of Traditional Chinese Medicine, Gan He Road 110, Shanghai, China. ${ }^{2}$ HanseMerkur Traditional Chinese Medicine Centre at University medical centre Hamburg-Eppendorf, Martinistrasse 52, Hamburg, Germany.

${ }^{3}$ Laboratory for Research and Diagnostics, Department of Maxillofacial Surgery and Neurology, University Medical Center Hamburg-Eppendorf, Martinistrasse 52, Hamburg, Germany. ${ }^{4}$ Gynecology Department, Shanghai Shuguang Hospital affiliated to Shanghai University of Traditional Chinese Medicine, Pu An Road 185, Shanghai, China. ${ }^{5}$ Shanghai University of Traditional Chinese Medicine, Cai Lun Road 1200, Shanghai, China.

\section{Authors' contributions}

LWX: principle investigator of the study, coordinating the study, analyzing the data and preparing the manuscript. LK: evaluating the data, correcting the manuscript. TTZ: coordinating the study and correcting the manuscript. SNL and YYM: Performing the study and analyzing the data. ZS, JM and XL: Performing the study. ZJS: Supervising the work and coordinating the study. All authors read and approved the final manuscript.

\section{Competing interests}

The authors declare that they have no competing interests.

Received: 29 June 2011 Accepted: 30 December 2011

Published: 30 December 2011

\section{References}

1. Utian WH, Archer DF, Bachmann GA, Gallagher C, Grodstein F, Heiman JR, Henderson WW, Hodis HN, Karas RH, Lobo RA, Manson JE, Reid RL, Schmidt PJ, Stuenkel CA, North American Menopause Society: Estrogen and progestogen use in postmenopausal women: July (2008) position statement of The North American Menopause Society. Menopause 2008 15(4 Pt 1):584-602.

2. Nelson HD: Commonly used types of postmenopausal estrogen for treatment of hot flashes: scientific review. JAMA 2004, 291(13):1610-1620.

3. Beral V, Reeves G, Bull D, Green J, Million Women Study Collaborators: Breast cancer risk in relation to the interval between menopause and starting hormone therapy. J Natl Cancer Inst 2011, 103(4):296-305.

4. Lacey JV Jr, Brinton LA, Leitzmann MF, Mouw T, Hollenbeck A, Schatzkin A Hartge P: Menopausal hormone therapy and ovarian cancer risk in the National Institutes of Health-AARP Diet and Health Study Cohort. J Nat Cancer Inst 2006, 98(19):1397-1405.

5. Furness S, Roberts H, Marjoribanks J, Lethaby A, Hickey M, Farquhar C: Hormone therapy in postmenopausal women and risk of endometrial hyperplasia. Cochrane Database Syst Rev 2009, , 2: CD000402. 
6. Beral V, Bull D, Reeves G, Million Women Study Collaborators: Endometrial cancer and hormone-replacement therapy in the Million Women Study. Lancet 2005, 365(9470):1543-1551.

7. Farquhar C, Marjoribanks J, Lethaby A, Suckling JA, Lamberts Q: Long term hormone therapy for perimenopausal and postmenopausal women. Cochrane Database Syst Rev 2009, , 2: CD004143.

8. Xu LW, Zhang SJ, Sun ZJ: The Traditional Chinese Medicine characteristics of etiology and pathogenesis of Menopausal Syndrome (围绝经期综合 征病因病机特点的思考). Journal of Traditional Chinese Medicine 2008, 49(11):1031-1033, (article in Chinese).

9. Nilsen J: Estradiol and neurodegenerative oxidative stress. Front Neuroendocrinol 2008, 29(4):463-475.

10. Miquel J, Economos AC, Fleming J, Johnson JE Jr: Mitochondrial role in cell aging. Exp Gerontol 1980, 15(6):575-591.

11. Mizuno $K$, Kume T, Muto C, Takada-Takatori Y, Izumi Y, Sugimoto $H$, Akaike A: Glutathione biosynthesis via activation of the nuclear factor E2-related factor 2 (Nrf2)-antioxidant-response element (ARE) pathway is essential for neuroprotective effects of sulforaphane and 6(methylsulfinyl) hexyl isothiocyanate. J Pharmacol Sci 2011, 115(3):320-328.

12. Sang $Z, X u L W$ : The clinical observation of 89 cases for Tiao Geng Tang balancing yin and yang on menopausal syndrome (中药调更汤改善围 绝经期综合征患者阴阳失衡状态89例临床观察). Jiang-su TCM Journal 2006, 27(5):79-80, (article in Chinese).

13. Downs JL, Wise PM: The role of the brain in female reproductive aging. Mol Cell Endocrinol 2009, 299(1):32-38.

14. Morrison SF: 2010 Carl Ludwig Distinguished Lectureship of the APS Neural Control \& Autonomic Regulation Section: Central Neural Pathways for Thermoregulatory Cold Defense. J Appl Physiol 2011, 110(5):1137-1149.

15. Shibasaki M, Crandall CG: Mechanisms and controllers of eccrine sweating in humans. Front Biosci (Schol Ed) 2010, 2:685-696.

16. Kalsbeek A, Yi CX, la Fleur SE, Buijs RM, Fliers E: Suprachiasmatic nucleus and autonomic nervous system influences on awakening from sleep. Int Rev Neurobiol 2010, 93:91-107.

17. Rosen HJ, Levenson RW: The emotional brain: combining insights from patients and basic science. Neurocase 2009, 15(3):173-181.

18. Smith PM, Ferguson AV: Circulating signals as critical regulators of autonomic state-central roles for the subfornical organ. Am J Physiol Regul Integr Comp Physiol 2010, 299(2):R405-415.

19. Casper RF: Clinical manifestations and diagnosis of menopause. UpToDate 2009, [cited 2011 Jun, version 19.3]. Available from: http://www.uptodate. $\mathrm{com} /$ contents/clinical-manifestations-and-diagnosis-of-menopause.

20. Wilson ME, Rosewell KL, Kashon ML, Shughrue PJ, Merchenthaler I, Wise PM: Age differentially influences estrogen receptor-alpha (ERalpha) and estrogen receptor-beta (ERbeta) gene expression in specific regions of the rat brain. Mech Ageing Dev 2002, 123(6):593-601.

21. Bao JZ, Ni CR, Zheng WQ: Age-related effects of estrogen on the expression of estrogen receptor alpha and beta mRNA in the ovariectomized monkey hypothalamus. Neurosci Bul 2006, 22(2):97-102.

22. Rachoń $D$, Vortherms $T$, Seidlová-Wuttke $D$, Wuttke W: Effects of black cohoshextract on body weight gain, intra-abdominal fat accumulation, plasma lipids and glucose tolerance in ovariectomized Sprague-Dawley rats. Maturitas 2008, 60(3-4):209-215.

23. Zhang J, Shen YL, Liu J, Wei D: Antimetastatic effect of prodigiosin through inhibition of tumor invasion. Biochem Pharmacol 2005, 69(3):407-414

24. Justo R, Frontera M, Pujol E, Rodríguez-Cuenca S, Lladó I, García-Palmer FJ, Roca P, Gianotti M: Gender-related differences in morphology and thermogenic capacity of brown adipose tissue mitochondrial subpopulations. Life Sci 2005, 76(10):1147-1158.

25. Bannister JV, Bannister WH, Rotilio G: Aspects of the structure, function, and applications of superoxide dismutase. CRC Crit Rev Biochem 1987, 22(2):111-180.

26. Apak R, Güçlü K, Ozyürek M, Bektașoğlu B, Bener M: Cupric ion reducing antioxidant capacity assay for antioxidants in human serum and for hydroxyl radical scavengers. Methods Mol Biol 2010, 594:215-239.

27. Del Rio D, Stewart AJ, Pellegrini N: A review of recent studies on malondialdehyde as toxic molecule and biological marker of oxidative stress. Nutr Metab Cardiovasc Dis 2005, 15(4):316-328.
28. Shen P, Guo BL, Gong Y, Hong DY, Hong Y, Yong EL: Taxonomic, genetic, chemical and estrogenic characteristics of Epimedium species. Phytochemistry 2007, 68(10):1448-1458.

29. Adams MM, Fink SE, Shah RA, Janssen WG, Hayashi S, Milner TA, McEwen BS, Morrison JH: Estrogen and aging affect the subcellular distribution of estrogen receptor-alpha in the hippocampus of female rats. J Neurosci 2002, 22(9):3608-3614.

30. Rune GM, Wehrenberg U, Prange-Kiel J, Zhou L, Adelmann G, Frotscher M: Estrogen up-regulates estrogen receptor alpha and synaptophysin in slice cultures of rat hippocampus. Neuroscience 2002, 113(1):167-175.

31. Inaba T, Matsuyama S, Takamori Y, Torii R, Takano H, Tamada H, Sawada T: Enhancement of estrogen receptor gene expression in the mediobasal hypothalamus during anestrus in the beagle bitch. Neurosci Lett 1997, 227(3):149-152.

32. Zhang YS, Xu YX, Chen CS, Chen GZ, Weng ZX, Yao Y: Effects of laser irradiation of acupuncture points Shenshu on ovariectomized rats. Photomed Laser Surg 2011, 29(4):271-275.

33. Wu M, Zhao $S$, Ren $L$ : Effects of total flavonoids of Epimedium sagittatum on the mRNA expression of the estrogen receptor $a$ and $\beta$ in hypothalamus and hippocampus in ovariectomized rats. Zhong Nan Da Xue Xue Bao Yi Xue Ban 2011, 36(1):15-20.

34. Shughrue PJ, Lane MV, Merchenthaler I: Comparative distribution of estrogen receptor-alpha and -beta mRNA in the rat central nervous system. J Comp Neurol 1997, 388(4):507-525.

35. Patisaul HB, Whitten PL, Young L: Regulation of estrogen receptor beta mRNA in the brain: opposite effects of 17beta-estradiol and the phytoestrogen, coumestrol. Brain Res Mol Brain Res 1999, 67(1):165-171.

36. Wang $Y K$, Huang ZQ: Protective effects of icariin on human umbilical vein endothelial cell injury induced by $\mathrm{H} 2 \mathrm{O} 2$ in vitro. Pharmacol Res 2005, 52(2):174-182.

37. Chang MS, Kim WN, Yang WM, Kim HY, Oh JH, Park SK: Cytoprotective effects of Morinda officinalis against hydrogen peroxide-induced oxidative stress in Leydig TM3 cells. Asian J Androl 2008, 10(4):667-674.

38. Chae HJ, Kim HR, Kim DS, Woo ER, Cho YG, Chae SW: Saeng-Ji-Hwang has a protective effect on adriamycin-induced cytotoxicity in cardiac muscle cells. Life Sci 2005, 76(18):2027-2042.

39. Zhang J, Zhang M, Sugahara K, Sagara Y, Meng Z, Xu S, Kodama H: Effect of steroidal saponins of Anemarrhenae rhizoma on superoxide generation in human neutrophils. Biochem Biophys Res Commun 1999, 259(3):636-639.

40. Kaname N, Zhang J, Meng Z, Xu S, Sugahara K, Doi Y, Kodama H: Effect of timosaponin E1 and E2 on superoxide generation induced by various stimuli in human neutrophils and on platelet aggregation in human blood. Clin Chim Acta 2000, 295(1-2):129-140.

41. Borrás C, Gambini J, López-Grueso R, Pallardó FV, Viña J: Direct antioxidant and protective effect of estradiol on isolated mitochondria. Biochim Biophys Acta 2010, 1802(1):205-211.

42. Rattanajarasroj S, Unchern S: Comparable attenuation of Abeta(25-35)induced neurotoxicity by quercitrin and 17 beta-estradiol in cultured rat hippocampal neurons. Neurochem Res 2010, 35(8):1196-1205.

43. Viña J, Sastre J, Pallardó FV, Gambini J, Borrás C: Modulation of longevityassociated genes by estrogens or phytoestrogens. Biol Chem 2008, 389(3):273-277.

44. Pedram A, Razandi M, Wallace DC, Levin ER: Functional estrogen receptors in the mitochondria of breast cancer cells. Mol Biol Cell 2006, 17(5):2125-2137

45. Stirone C, Duckles SP, Krause DN, Procaccio V: Estrogen increases mitochondrial efficiency and reduces oxidative stress in cerebral blood vessels. Mol Pharmacol 2005, 68(4):959-965.

\section{Pre-publication history}

The pre-publication history for this paper can be accessed here: http://www.biomedcentral.com/1472-6882/11/137/prepub

doi:10.1186/1472-6882-11-137

Cite this article as: Xu et al:: Chinese herb mix Tiáo-Gēng-Tāng possesses antiaging and antioxidative effects and upregulates expression of estrogen receptors alpha and beta in ovariectomized rats. BMC Complementary and Alternative Medicine 2011 11:137. 